ISSN 1984-3755

Licenciado sob uma Licença Creative Commons

\title{
Eucaristia e Teologia no Vaticano II ${ }^{1}$
}

\author{
Eucharist and Theology in Vatican II
}

\section{Ghislain Lafont}

Professor emérito de Teologia na Pontifícia Universidade Gregoriana e no Pontifício Ateneu Santo Anselmo, em Roma; monge beneditino da Abadia de Sainte Marie de la Pierre-Qui-Vire, em Saint Léger Vauban - França, e-mail: f.ghislain@apqv.fr

\section{Resumo}

A premissa hermenêutica explicitada pelo autor é que os textos eucarísticos do Vaticano II são lidos sobre o pano de fundo da prática litúrgica dos últimos 50 anos. A partir deste contexto histórico vital, recupera o projeto fundador do Concílio, intuído por João XXIII e que a Sacrosanctum Concilium exprime em seu proêmio: "O Sacrossanto Concílio propõe-se a fomentar sempre mais a vida cristã entre os fiéis; acomodar meIhor às necessidades de nossa época as instituições que são suscetíveis de mudanças; favorecer tudo o que possa contribuir para a união dos que creem em Cristo; e promover tudo o que conduz ao chamamento de todos ao seio da lgreja. Por isso, julga seu dever cuidar de modo especial da reforma e do incremento da liturgia" (SC 1). Segundo o autor, o fundamento trinitário da Igreja (Ecclesia a Trinitate) - tal qual aparece na

1 Conferência no $22^{\circ}$ Congresso da Associação Teológica Italiana, Turim, 29-8 a 2-9.2011. Texto gentilmente cedido à Pístis \& Práxis. Tradução: Prof. Dr. Antonio José de Almeida. 
própria Sacrosantum Concilium (SC 3, 5 e 6), na Dei Verbum (DV 2-4), na Lumen gentium (LG 2-4) e no decreto Ad gentes (AG 2-4) - constitui a impostação eclesiológica fundamental do Concílio. O mistério cristão, do qual a Igreja constitui sinal e gérmen na história, não é senão o dom do Filho pelo Pai no Espírito, que, acolhido na fé por graça, nos torna filhos e filhas do Pai, irmãos e irmãs entre nós, participantes da vida dada e recebida de Deus. O dom do corpo (Ceia) e o dom do Espírito (Pentecostes) são os dois polos desta comunicação. Essa é a "tradição viva", memória do evento Cristo recebida do Pai, viva e vivida na Igreja graças ao Espírito. Igreja, eucaristia e Teologia vivem desta mesma lógica do dom e da acolhida, coração do Mistério que se tornou carne e culto e salvação em Jesus.

Palavras-chave: Igreja. Eucaristia. Trindade. Tradição. Dom.

\section{Abstract}

The hermeneutic premise explained by the author is that the Eucharistic texts of Vatican II are read upon the background of the liturgical practice of the last fifty years. From this vital historical context, it retrieves the founding project of the Council, intuited by John XXIII and that the Sacrosanctum Concilium expresses in its prologue: "The sacred council intends to encourage more and more the Christian life among the believers; to accommodate better to the needs of our time the institutions that are susceptible of change; to encourage anything that may contribute to the unity of all believers in Christ; and promote everything that leads to the call of all people the Church's bosom. So it judges its duty giving special care to the reform and the increase of the liturgy" (SC 1). According to the author, the trinitarian foundation of the Church (Ecclesia a Trinitate) - as it appears in the very Sacrosantum Concilium (SC 3, 5 and 6), in the Dei Verbum (DV 2-4), in the Lumen Gentium (LG 2-4) and in the Ad Gentes Decree (AG 2-4) - is the fundamental ecclesiological formulation of the Council. The Christian mystery, of which the Church is a sign and germ in history, is but the gift of the Son by the Father in the Spirit, who, having been received in faith by grace, makes us sons and daughters of the Father, brothers and sisters among us, participants of the life given and received from God. The gift of the body (the Holy Supper) and the gift of the Spirit (Pentecost) are the two poles of this communication. This is the "living tradition", memory of Christ-event received from the Father, living and lived within the Church through the Holy Spirit. The Church, Eucharist and theology live based on this 
same logic of the gift and hospitality, the very heart of the Mystery that became flesh and service and salvation in Jesus.

Keywords: Church. Eucharist. Trinity. Tradition. Gift.

Na medida em que entendo a função de uma comunicação no equilíbrio global de um congresso de Teologia, vejo duas possibilidades. A primeira seria clarificar um tema limitado, particular, pequeno, mas significativo, que possa ilustrar o conjunto daquilo que está em discussão, ou então aportar uma pedra, ainda que pequena, mas bem talhada, ao edifício total. A segunda seria propor uma perspectiva bem ampla para facilitar uma pesquisa sucessiva sobre o tema; em outras palavras, tentar uma impostação provisória que prepare um caminho e seja ulteriormente corrigida pelo próprio caminhar.

O tema que me foi proposto "Eucaristia e Teologia no Vaticano II" não é nem limitado, nem pequeno, nem particular. Escolhi, então, a segunda função de uma comunicação: abrir uma perspectiva.

\section{Premissas hermenêuticas}

Durante 50 anos, os textos do Vaticano II e justamente os eucarísticos têm conhecido uma Wirkungsgeschichte (literalmente, história do efeito - N.d.T.) teórica e prática muito movimentada, de modo que não é possível avançar seja a reflexão seja a prática sem tentar uma avaliação dessa história, a qual qualifica a nossa leitura atual.

A leitura hoje dos textos eucarísticos do Vaticano II desenvolve-se sobre o pano de fundo de 40 anos de prática litúrgica. Os livros litúrgicos promulgados por Paulo VI tornaram-se, diria, o bem comum quotidiano da Igreja, concretamente, das paróquias. O uso da língua vernácula facilitou o acesso a eles, de modo que as fórmulas, de alto significado teológico, entraram na memória de todos os fiéis e a marcaram sem que todos fossem totalmente conscientes disso. Do mesmo modo, a diversidade e a riqueza dos textos bíblicos penetraram pouco a pouco o coração dos ouvintes, tanto mais 
que, com muita frequência, a primeira e a segunda leituras da Liturgia da Palavra da missa são feitas pelos próprios fiéis. Ademais, de tanto em tanto, nas paróquias, há reuniões, cursos e encontros de formação, para ajudar a entender melhor o sentido da liturgia habitualmente celebrada. Ora, tal prática habitual constitui o pano de fundo sobre o qual nós lemos os textos do Vaticano II e ela nos garante, em certa maneira, uma hermenêutica adequada.

Tratando-se da liturgia, isto é, do lugar do encontro vivo e real com o Mistério de Cristo hoje, é normal que a nossa leitura dos textos do Vaticano II tenha sido marcada pela história contemporânea, fruto de um conjunto de eventos imprevisíveis ao tempo do Concílio. A virada cultural foi e continua a ser ingente. Não é o caso de analisá-la aqui, mas gostaria de fazer uma pequena lista de expressões que qualificam o ambiente geral no qual estamos celebrando a Eucaristia e os outros gestos litúrgicos da Igreja: hegemonia do virtual sobre o real, e ainda o espaço-temporal; hegemonia da imagem em prejuízo da palavra e da escrita; mundialização problemática; situação conflitual das religiões (Judaísmo x Islamismo, Islamismo x Cristianismo); diálogo com as sabedorias orientais e o fascínio do apofático, para além da palavra bem como dos sinais. Poder-se-ia alongar a lista. Basta dizer que o ambiente atual não é tão congenial à essência simbólico-real da liturgia cristã e que temos que lutar para mantê-la não de modo polêmico, mas também para ajudar, talvez, o próprio mundo a encontrar atitudes humanas e religiosas que certamente lhe faltam cruelmente. Lutar também para não contaminar a liturgia com elementos que lhe são estranhos.

Enfim, não podemos ler os textos do Vaticano II sem levar em conta o fato de que a Wirkungsgeschichte tornou-se, em certos círculos, uma 'Kriegsgeschichte' (literalmente, história de guerra - N.d.T.), guerra litúrgica, 'Zerstörungsgeschichte' (história de destruição), história de uma tentativa de destruição. Talvez estes tristes episódios favoreçam uma 'Essenzialsgeschichte' (literalmente, história do essencial - N.d.T.): por meio das discussões, pode-se, pouco a pouco, ser conduzido ao essencial.

Uma definição mais precisa das dimensões de uma tão polivalente Wirkungsgeschichte do Concílio e da liturgia em particular não pode ser desenvolvida nesta ocasião. Tenha-se presente, porém, que, para um estudo mais preciso, a reconstituição dessa história é uma etapa necessária e deve ser mantida no horizonte de qualquer reflexão. 


\section{0 projeto fundador do Concílio e a Eucaristia}

\section{Uma leitura da Sacrosanctum Concilium 1}

Não podendo resgatar toda a discussão hermenêutica sobre o Concílio, gostaria de iniciar esta breve comunicação com o n. 1 da Constituição Sacrosanctum Concilium, porque ele indica pelo menos uma perspectiva para impostar o nosso tema.

O Sacrossanto Concílio propõe-se a fomentar sempre mais a vida cristã entre os fiéis; acomodar melhor às necessidades de nossa época as instituições que são suscetíveis de mudanças; favorecer tudo o que possa contribuir para a união dos que creem em Cristo; e promover tudo o que conduz ao chamamento de todos ao seio da Igreja. Por isso, julga seu dever cuidar de modo especial da reforma e do incremento da liturgia (CONCÍLIO VATICANO II) ${ }^{2}$.

Aqui, ressoa a famosa homilia de João XXIII na abertura do Concílio, cujo escopo, segundo o papa, deveria ser uma tríplice unidade: da Igreja católica, sólida e exemplar; dos cristãos e cristãs pertencentes às outras confissões cristãs; dos homens e mulheres que aderem a outras religiões e que são, na verdade, a maioria (ALBERIGO, 1989, p. 184).

A reforma litúrgica e, portanto, a reforma da Eucaristia, que é o seu centro - talvez com o olhar voltado para outras liturgias - deveria ter, portanto, um alcance universal.

\section{O fundamento da "unidade sólida e exemplar dos católicos"}

\section{A impostação basilar do Concílio: "Ecclesia a Trinitate"}

Durante o verão, tive a oportunidade de ir à África para estudar com um grupo de monges os textos do Vaticano II e pude verificar, como já o tinha feito no Vietnam em 2010, que esses documentos eram quase totalmente desconhecidos.

2 Sacrosanctum Concilium 1. 
Dei-me conta, então, de que os textos relativos à Igreja em si mesma são permeados, penetrados, por uma única intuição de conjunto, expressa no início das constituições sobre a Revelação Dei Verbum (DV 2-4), sobre a Liturgia Sacrosanctum Concilium (SC 3, 5 e 6), sobre a Igreja Lumen gentium (LG 2-4) e no decreto Ad gentes (AG 2-4), que poderia ser resumida na fórmula "Ecclesia a Trinitate". Esta seria a impostação geral do Concílio Vaticano II.

1) Todo o Mistério cristão tem seu ponto de partida no desígnio inicial que brota da bondade do Pai: de comunicar-se aos homens em amizade, no Filho, mediante o Espírito Santo, e de dar participação à sua natureza divina ('amizade', para dizer uma relação interpessoal; 'participação', para dizer uma comunicação de essência).

2) Este desígnio, que explica toda a economia da criação e da salvação, realiza-se em Cristo, Verbo encarnado, que se manifestou depois de um longo processo que vai de Abraão a João Batista e comunica o desígnio de Deus por meio da sua pregação ligada às Escrituras, os eventos da sua vida, a convivialidade com os discípulos, os sinais e os símbolos utilizados, e, finalmente, a sua morte e a sua ressurreição.

3) O dom do Pai e a sua manifestação em Cristo são propostos, acolhidos e vividos na Igreja pela mediação do Espírito, mandado pelo Cristo ressuscitado justamente para o entendimento sempre renovado e a tradução em obras do Mistério revelado e dado.

\section{Rumo a um conceito globalizante da expressão "Tradição cristã"}

Neste sentido, a Tradição cristã pode ser dita a memória do evento Cristo recebida do Pai, viva e vivida na Igreja graças ao Espírito. Todo o tempo depois de Cristo pode ser compreendido como a duração, não ainda terminada, da realização progressiva do desígnio do Pai; a resposta que a Igreja lhe dá; o confronto que estabelece entre o Mistério dado e a humanidade que o recebe. 


\section{Os dons do evento Cristo}

Os dois grandes dons nos quais todo o evento Cristo é compendiado são os do seu Corpo, dado na Última Ceia, e do seu Espírito, prometido antes da morte e derramado depois da Ressurreição. O dom do corpo não é separado da história da salvação, de todo a espessura da Revelação divina na história, evocada nas Escrituras recitadas durante o rito e repetidas pelo Senhor depois da Ressurreição. O Espírito, por sua vez, ilumina as Escrituras, inspira as palavras e os novos escritos, anima os gestos e opera o encontro do Mistério com a humanidade de cada época. A Eucaristia seria, assim, o lugar comunitário, eclesial, onde convergem a Palavra de Deus, a carne de Cristo, o sopro do Espírito. O lugar em que o Mistério é "entregue" (traditum). Tradição (traditio) é "entrega"!

\section{A recepção ativa desses dons}

A tradição (processo de entrega e de acolhida) do Mistério não é superficial, não está acima dos que a recebem: é dada enquanto transforma; no momento mesmo em que é dada, ela é devolvida Aquele que dá. Os textos do capítulo II sobre o povo de Deus, na Lumen gentium, são muito claros: colocam em luz a reciprocidade constante entre o dom de Deus e o sacrifício (entrega) dos homens e mulheres. Vale a pena, a esta altura, relê-los atentamente.

LG 9:

O povo messiânico tem por cabeça Cristo, "o Qual foi entregue por nossos pecados e ressuscitou para a nossa justificação" ( $R m$ 4,25), e agora, tendo conseguido um nome que está sobre todo o nome, reina gloriosamente nos céus. Tem por condição a dignidade e a liberdade dos filhos de Deus, em cujos corações habita o Espírito Santo como num templo. Sua lei é o mandamento novo de amar como o próprio Cristo nos amou (cf. Jo 13,34). Sua meta é o reino de Deus, iniciado pelo próprio Deus na terra, a ser estendido mais e mais até que no fim dos tempos seja consumado por Ele próprio, quando aparecer Cristo, nossa vida (cf. $\mathrm{Cl} 3,4$ ) e a própria criatura será libertada do cativeiro da corrupção para a gloriosa liberdade dos filhos de Deus (Rm 8,21).

Eis o dom. 
Agora, a resposta - LG 10:

Pela regeneração e unção do Espírito Santo, os batizados são consagrados como casa espiritual e sacerdócio santo, para que, por todas as obras do homem cristão, ofereçam sacrifícios espirituais e anunciem os prodígios dAquele que das trevas os chamou à sua luz admirável (cf.1 Pd 2,4-10).

Esta frase é imediatamente repetida nas linhas sucessivas como para dizer quanto é importante sublinhar os dois elementos da resposta humana ao dom de Deus: sacrifício espiritual da vida; testemunho.

É interessante notar que as mesmas palavras são usadas no parágrafo sobre a função profética do povo de Deus, já no início do n. 12:

O povo santo de Deus participa também do múnus profético de Cristo, pela difusão do seu testemunho vivo, sobretudo através de uma vida de fé e caridade, e pelo oferecimento a Deus do sacrifício de louvor, fruto de lábios que confessam o seu nome ( $\mathrm{Hb} 13,15)$.

Finalmente, encontramos a mesma doutrina no início do decreto sobre os presbíteros, Presbyterorum ordinis.

\section{PO 2:}

O Senhor Jesus, "a quem o Pai santificou e enviou ao mundo" (Jo 10,36), faz todo o seu corpo místico participar da unção do Espírito pela qual ele foi ungido. Pois nele os fiéis tornam-se um sacerdócio santo e régio, oferecem a Deus hóstias espirituais por Jesus Cristo, e anunciam as virtudes daquele que das trevas os chamou para sua luz admirável.

"Santificar Jesus Cristo no seu coração" e "dar testemunho de Jesus com espírito de profecia", eis, pois, as duas modalidades intrinsecamente ligadas da resposta ao dom de Deus. Dar testemunho da munificência divina é um ato sacerdotal; oferecer-se a Deus em sacrifício espiritual é um ato profético. A atitude constitutiva da vida cristã é, ao mesmo tempo, sacrifício e testemunho, e se realiza no momento mesmo no qual a comunidade recebe o dom da Memória de Cristo.

Como o explica, em seguida, o próprio texto do decreto Presbyterorum ordinis, inspirando-se na doutrina agostiniana exposta no De Civitate Dei, livro X, 
a celebração eucarística manifesta-se como a prática mediante a qual a Tradição do Mistério é comunicada pelo Pai, acolhida e dada a Ele, que é a sua origem. A celebração eucarística é um receber de Deus: (literalmente, "recezione da Dio": este 'da' indica origem - N.d.T.): seja pelas leituras das Escrituras que o exprimem, seja pela anamnese do Mistério de Jesus morto e ressuscitado, seja pela repetição das palavras e dos gestos da narração pascal, seja pelo dom do Espírito ativo em tudo isto, a celebração eucarística opera em meio a nós a tradição (entrega) e nos conforma a ela. Seria o sentido da fórmula: "Eucharistia facit ecclesiam". Mas a celebração eucarística é, simultaneamente, dom a Deus. Nesta, o fruto espiritual da existência humana, pessoal, comunitária, global, é ligado, unido ao sacrifício de Cristo, oferecido. A humanidade reconciliada à luz dos dois mandamentos do Evangelho oferece-se a Deus em Cristo. Seria o sentido da segunda fórmula, recíproca da primeira: "Ecclesia facit Eucharistiam".

Parece-me que as breves evocações dos textos conciliares nos ajudam a entender o alcance da definição/descrição da Eucaristia feita no n. 48 da Sacrosanctum Concilium:

[Nela, os fiéis] são formados pela palavra de Deus; são saciados à mesa do Corpo do Senhor; oferecendo a vítima sem mancha... aprendem a oferecer a si mesmos e, dia após dia, pela mediação de Cristo, são aperfeiçoados na unidade com Deus e entre si, de modo que Deus, finalmente, seja tudo em todos.

\section{Três pistas para um ulterior aprofundamento}

\section{Eucaristia, tempo e escatologia}

Poder-se-ia aprofundar a indicação dinâmica do texto: "dia após dia... aperfeiçoados". Poderia ser comentada com um inciso na fórmula já citada sobre o Reino de Deus de LG 9. Do Reino de Deus se diz que "deve ser ulteriormente expandido". Ora, o tempo da Igreja é justamente o da expansão do Reino, cadenciado pela celebração eucarística. Pode-se ligar a expressão com o breve desenvolvimento da Dei Verbum $\mathrm{n}^{\circ} 8$ sobre o progresso e o crescimento da Tradição rumo ao estado escatológico da Verdade. Para o nosso discurso, um aprofundamento é importante: o sacrifício espiritual e o testemunho da Igreja são qualificados pela situação 
efetiva dos homens e das mulheres, enquanto o sacrifício e o testemunho de Cristo, que provêm do alto, recapitulam, quiçá purificado na Eucaristia hoje celebrada, o sacerdócio efetivo e o testemunho real apresentados pelos homens e mulheres. Neste sentido, o processo indicado com as palavras fides et ratio é intrinsecamente ligado ao processo litúrgico.

\section{Um princípio sintético para os textos do Vaticano II}

Tal âmbito de reflexão pode introduzir a outro. Não se deveria estudar mais a conexão literária e doutrinal entre os capítulos I e II, de um lado, e VII, do outro, da Lumen gentium? A revelação cristã, expressa nos prólogos dos quatro documentos inicialmente mencionados, encarna-se no povo de Deus e nas suas atividades como é descrito no capítulo II da Lumen gentium, e só será perfeitamente cumprida na escatologia, quando Deus será tudo em todos. Na hipótese de uma continuidade total entre esses capítulos, não podemos imaginar uma impostação geral do Vaticano II? Os capítulos III a VI, sobre a constituição hierárquica, os leigos e os religiosos, respectivamente, completados pelos decretos correspondentes sobre os bispos (Christus Dominus), os presbíteros (Presbyterorum ordinis), leigos (Apostolicam actuositatem), religiosos (Perfectae charitatis), descrevem os estados de vida - leigo e religioso - e as estruturas ministeriais mediante as quais se cumpre progressivamente o desígnio revelado, ou seja, se realiza "o ulterior" que fiz questão de sublinhar. Ora, temos uma reflexão sobre as ordens da Igreja. A constituição pastoral sobre a Igreja no mundo Gaudium et spes, ao invés, descreve o programa e a realização do sacrifício espiritual que é oferecido a Deus em cada momento do tempo, em cada configuração do mundo, enquanto as suas dimensões se alargam ao longo dos tempos na direção da unidade suspirada. Relidas em chave escatológica, a reflexão e a práxis da Igreja no mundo deste tempo (que não é mais o tempo cronológico do Vaticano II) podem e devem ser vividas "eucaristicamente", isto é, a Eucaristia dá ao tempo dos homens o seu ritmo fundamental: renovando e aplicando hoje o dom de Deus em Cristo, atualizando hoje o sacrifício espiritual e o testemunho mediante os quais o dom é entregue ao Doador. Portanto, recordando-nos do $\mathrm{n}^{\circ} 1 \mathrm{da}$ constituição Sacrosanctum Concilium, podemos entrever como a Eucaristia se 
refere também a toda atividade, a todo ato religioso autêntico das diversas comunidades humanas e religiosas. Estamos, aqui, diante de uma perspectiva interessante para o exame e a avaliação dos decretos sobre o ecumenismo, de uma parte, e sobre as religiões e a liberdade religiosa, da outra.

\section{Para uma qualificação renovada da redenção: sacrifício espiritual e sacrifício redentor na Eucaristia}

Gostaria, finalmente, de sublinhar que, nos nossos textos, o sacrifício espiritual, ligado ao testemunho, é apresentado de maneira positiva. A referência ao pecado é escassa; a oferta da vida, pessoal e comunitária, sendo o dom eclesial que responde ao dom do Pai, iniciador da criação e da salvação, isto é, o chamado à amizade com Deus e à participação ao seu ser divino. Vejo aqui uma confirmação para o tema que procurei desenvolver em outro lugar, isto é, a distinção, no sacrifício de Cristo (e no da Igreja), entre a dimensão positiva do sacrifício de comunhão, onde o dom, isto é, a perda da vida, é totalmente positivo, e o sacrifício pelo pecado, que compreende os elementos negativos, dramáticos, ligados às feridas derivadas da recusa do sacrifício de comunhão.

Permitam-me citar, encerrando esta pequena comunicação, um diálogo de Christian de Chergé com um muçulmano sufi, sobre a Cruz (CHENU, 1996, p. 105).

Se falássemos da Cruz, diz o muçulmano.

- Qual?

- A de Jesus, obviamente,

- Sim, mas qual? Quando olhas a uma imagem de Jesus na cruz, quantas cruzes vês?

O muçulmano hesitou.

- Talvez três... seguramente duas: a da frente, a de trás.

- E qual provém de Deus?

- A da frente.

- E a dos homens?

- A de trás.

- Qual é a mais antiga? 
- A de frente... Os homens não puderam imaginar a outra, senão porque Deus tinha, antes, criado a primeira.

- E qual é o sentido desta Cruz de frente, deste homem com as mãos estendidas?

- Quando estendo as mãos, é para abraçar, para amar.

- E a outra?

- É o instrumento do amor infinito, desfigurado, do ódio que crava na morte o gesto da vida.

O amigo sufi tinha dito: "Talvez três". A terceira, não era eu, não era ele, neste esforço que nos levava a ambos a distanciar-nos da cruz "de trás", a do mal e do pecado, para aderir à "da frente", a do amor vencedor?"

Ora, o Senhor não se distanciou da cruz "de trás", assumiu-a totalmente, para transformá-la, porém, na cruz "da frente", sinal eterno do amor. Não seria a Eucaristia o lugar sempre renovado desta transformação na vida dos homens e das mulheres de cada hoje?

\section{Referências}

ALBERIGO, G. Jean XXIII et le Concile. In: ALBERIGO, G. (Ed.). Jean XXIII devant l'histoire. Paris: Éd. du Seuil, 1989. p. 176-216.

CHENU, B. Sept vies pour Dieu et l'Algérie. Paris: Centurion - Bayard, 1996. CONCÍLIO VATICANO II. Sacrosanctum Concilium 1. Disponível em: <http:// www.vatican.va/archive/hist_councils/ii_vatican_council/documents/vat-ii_ const_19631204_sacrosanctum-concilium_po.html>. Acesso em: 20 jun. 2011.

Recebido: 28/11/2011

Received: 11/28/2011

Aprovado: 01/02/2012

Approved: 02/01/2012 